\title{
Coronary Angiographic Profile in Patients with Conduction System Disorder Requiring Permanent Cardiac Pacing
}

\author{
AAS Majumder, MA Ali , MTBA Rashid \\ Department of Cardiology, NICVD, Dhaka
}

Key words:

Conduction

disturbances,

Permanent

pacemaker,

Coronary

angiogram,

Type of coronary

artery lesion.

\begin{abstract}
Background: The association between conduction disturbances and atherosclerotic coronary artery disease has been investigated in a few small studies in the early 1970s and the study result was inconclusive. Thereafter some investigators found in their separate study that a group of patients with conduction disturbances that required permanent pacemaker who had coronary atherosclerotic disease that might be responsible for conduction disturbances.

Method: 40 consecutive patients that required permanent pacemaker and 40 control patients were investigated. The coronary angiographic study was performed in both groups which included classification of pathological coronary anatomy, qualitative assessment of flow and stenosis severity.

Results: The location of the lesions was found significantly different between two groups. 14 patients(35\%) of 40 study patients had type IV lesion, whereas only 2 patients(5\%) of 40 control patients had type IV lesion ( $p=0.001$ ). Flow quality was found poor in more patients in study group specially that had type IV lesion. Severity of the lesions in the LAD \& RCA was found identical in both groups.

Conclusion: It may be concluded that the location of the lesions rather than diffuse coronary atherosclerosis might be responsible for a subset of patients with conduction disturbances that required permanent pacemaker.
\end{abstract}

(Cardiovasc. j. 2011; 4(1): 61-66)

\section{Introduction}

Cardiovascular disease is the highest killer in developed countries and is rapidly assuming a similar role in developing ones. It has been predicted that cardiovascular diseases will be the most important cause of mortality by the year 2015. Bangladesh is a small country with vast population. Cardiovascular diseases are becoming a significant burden on health care services in Bangladesh. ${ }^{1}$

Conduction disturbance of the heart may affect the sinoatrial and $\mathrm{A}-\mathrm{V}$ nodes and the intraventricular conduction system.Heart block and conduction disturbances appear to be relatively common in general population. Many individuals with conduction system disorder are asymptomatic and never seek medical attention. ${ }^{2-4}$

Clinical presentation of symptomatic patients may range from exercise intolerance, easy fatigability, dysponea on exertion, chest pain, dizzy spells and near syncope to frank syncope. In general, it is difficult to ascribe conduction system disease to a specific cause, at least in adults. Although it is true that many of these patients have heart disease, usually ischemic, a cause-and-effect relationship is difficult to document. In fact, unless the conduction defect occurred in the setting of acute myocardial infarction, histologic examination of the conduction system in most of these individuals shows nonspecific scarring and fatty infiltration regardless of the presence or absence of underlying ischemic heart disease. ${ }^{5}$

According to Rossi, the histologic changes in the conduction system are not sufficient to explain the disorder, so that the associated disease condition, whether coronary atherosclerosis, hypertensive cardiovascular disease, or myocardial disease, must be considered important in the pathogenesis of the conduction defect. Where advanced atherosclerosis is held responsible, the lesion would presumably have to be an extensive one. ${ }^{6}$

Address of Correspondence: Prof. Abdullah Al Shafi Majumder, Prof. of Cardiology, Department of Cardiology, NICVD, Dhaka, Bangladesh. 
Because conduction disorder is a heterogenous entity of diverse causes, treatment options may vary from individuals to individual, depending upon the specific cause and clinical manifestations. Permanent pacing is the cornerstone of treatment for most patient with symptomatic conduction system disease, but other therapeutic options may be helpful in addition to permanent pacemaker where identifiable cause is found. ${ }^{5}$

Ischemic heart disease is an important cause of heart block and conduction disturbances where in addition to permanent pacemaker other medication may be helpful for better patient management. ${ }^{5}$

Coronary angiogram is the most appropriate tool for the identification of ischemic heart disease and their correlation with severe conduction disturbances that require implantation of permanent pacemaker. Coronary angiogram more specifically identified the specific pathological coronary anatomy that might be responsible for conduction disturbances. The location of the lesion in the coronary tree rather than severe diffuse atherosclerosis appears to be responsible for the conduction disturbances. ${ }^{7}$

In clinical practice most of the patients aged 40 or above with conduction system disease present with chest pain or discomfort in addition to symptoms related to bradyarrythmia. However these symptoms are underestimated and seldom evaluated. The study done by Morris Mosseri et al. ${ }^{7}$ advocated CAG in these patients. So in perspective of our country this study aims to identify the undiagnosed cause of conduction system disease that require permanent pacemaker and will facilitate patient management in a better way.

\section{Study Method:}

This is the prospective observational study carried out at the Department of Cardiolgy, NICVD, Dhaka from the period of $1^{\text {st }}$ January 2006 to $31^{\text {st }}$ December 2007.

Total 80 subjects of both sexes of whom 40 had conduction system disorder requiring permanent cardiac pacing were in group I and 40 had no conduction system disorder but known coronary artery disease having similar risk factor were included in group II.

History, clinical examination and baseline investigation was done at both groups of patients. Permanent pacemaker was implanted in all study patients as clinical parameter and ECG findings indicated permanent cardiac pacing.

Coronary angiography was performed with the standard Judkins approach in all study patients within two months before or after pacemaker implantation and also in all control patients. Angiograms were reviewed by two experienced observers who were unaware of clinical data of patients. Significant coronary artery disease was defined as narrowing of $>50 \%$ of the coronary artery luminal diameter. The dominance of the coronary tree was determined and documented according to the criteria of Dodge et al. ${ }^{8}$

The location of narrowings in LAD and RCA as the arteries supplying the conduction system was documented accurately and classified as follows-

Type I: Anatomy not compromising blood supply to the conduction system, either the absence of significant narrowing in LAD, RCA, LCX, PL (Postero-lateral),or PDA or presence of mid-distal LAD lesions past the septal branches.

Type II: Pathological coronary anatomy involving septal branches emerging from $\mathrm{LAD}$ (and without significant lesions in the RCA).

Type III: Pathological coronary anatomy compromising blood supply to the SA or AV node but not compromising blood flow to the septal branches. This subset included patients with distal LAD lesions after the septal branches.

Type IV: Combinations of types II and IIIPathological coronary anatomy that compromises blood supply both the septal branches and to the SA or AV branch.

\section{Results}

Demographic profile of both groups were shown in the tables(I,II \& III) which reveled there was no significant difference in terms of age, sex \& risk factor profiles in both study group \& control group. 

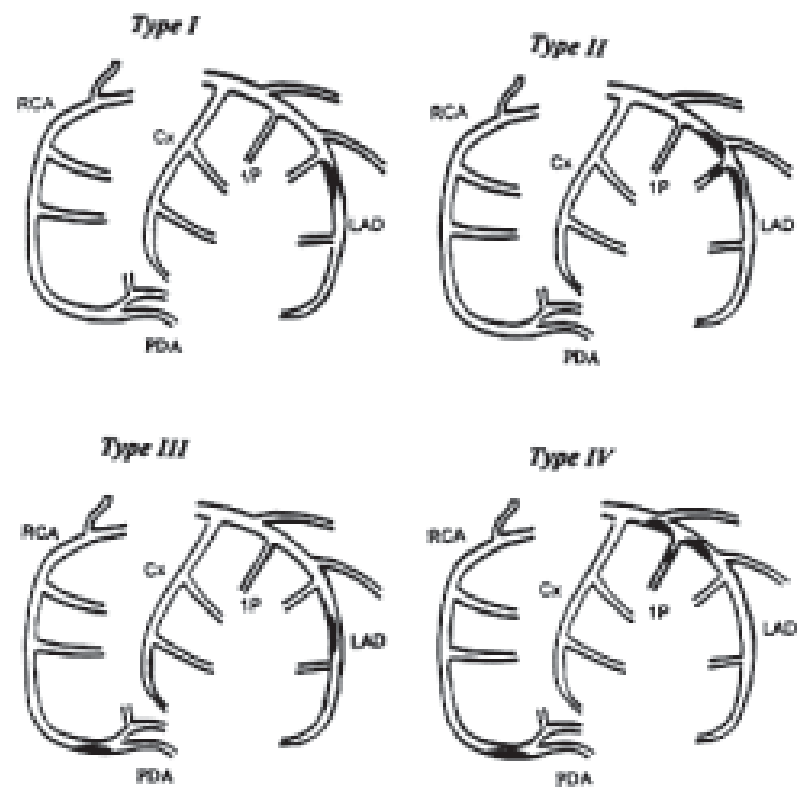

Fig.-1: Classification of pathological coronary anatomy supplying the conduction system: type I, lesions not related to septal branches or the AVnode; type II, lesions compromising blood supply to septal branches emerging from the LAD; type III, lesions compromising blood supply to the AV node; and type $I V$, lesions compromising blood supply both to septal branches emerging from the $L A D$ and to the $A V$ node. P indicates perforator; Cx, circumflex artery. (Circulation. 1997;96:809-815.)

Table-I

Distribution of the subjects by age $(N=80)$

\begin{tabular}{lcccccr}
\hline Age in & \multicolumn{2}{c}{ Group I } & & \multicolumn{2}{c}{ Group II } & \multirow{2}{P}{} \\
\cline { 2 - 3 } years & $\mathrm{n}$ & $\%$ & & $\mathrm{n}$ & $\%$ & Value \\
\hline $30-40$ & 6 & 15.0 & & 3 & 7.5 & \\
$41-50$ & 8 & 20.0 & & 18 & 45.0 & \\
$51-60$ & 13 & 32.5 & & 11 & 27.5 & \\
$61-70$ & 10 & 25.0 & & 20.0 & \\
$71-80$ & 3 & 7.5 & & 0 & 0.0 & \\
Mean \pm SD & 55.1 & \pm 11.4 & & 51.4 & \pm 8.8 & $0.112^{\mathrm{NS}}$ \\
\hline
\end{tabular}

$\mathrm{NS}=$ non significant

Table-II

Distribution of the subjects by sex $(N=80)$

\begin{tabular}{lcccccr}
\hline Sex & \multicolumn{2}{c}{ Group I } & & \multicolumn{2}{c}{ Group II } & P \\
\cline { 2 - 3 } & $\mathrm{n}$ & $\%$ & & $\mathrm{n}$ & $\%$ & Value \\
\hline Male & 34 & 85.0 & & 32 & 80.0 & \\
Female & 6 & 15.0 & & 8 & 20.0 & $0.556^{\text {NS }}$ \\
\hline Total & 40 & 100.0 & 40 & 100.0 & \\
\hline
\end{tabular}

$\mathrm{NS}=$ non significant

Table-III

Distribution of the patients in both groups according to risk factor for conduction system disease $(N=80)$

\begin{tabular}{lcccccr}
\hline & \multicolumn{2}{c}{ Group I } & & \multicolumn{2}{c}{ Group II } & P \\
\cline { 2 - 3 } & $\mathrm{n}$ & $\%$ & & $\mathrm{n}$ & $\%$ & Value \\
\hline HTN & 21 & 52.5 & & 19 & 47.5 & $0.654^{\mathrm{NS}}$ \\
DM & 11 & 27.5 & & 10 & 25.0 & $0.469^{\mathrm{NS}}$ \\
LV dysfunction & 8 & 20.0 & & 11 & 27.5 & $0.133^{\mathrm{NS}}$ \\
\hline
\end{tabular}

$\mathrm{NS}=$ non significant

Table-IV

Indication of PPM implantation in study population $(n=40)$

\begin{tabular}{lcc}
\hline Indication of PPM & \multicolumn{2}{c}{ Group I } \\
\cline { 2 - 3 } Implantation & $\mathrm{n}$ & $\%$ \\
\hline Symptomatic nodal bradycardia & 4 & 10.0 \\
Symptomatic CHB & 28 & 70.0 \\
SSS & 2 & 5.0 \\
Mobitz type II A.V block with H/O & 3 & 7.5 \\
syncopal attack & & \\
Bifascicular block & 1 & 2.5 \\
Symptomatic 2:1 AV block & 2 & 5.0 \\
\hline
\end{tabular}

Distribution of severity of lesions at LAD \& RCA was found insignificant in both groups.

Table-V

Distribution of the patients in both groups according to severity of lesions at LAD

$(N=80)$

\begin{tabular}{lcccccr}
\hline Severity of lesion & \multicolumn{2}{l}{ Group I } & & \multicolumn{2}{c}{ Group II } & \multicolumn{1}{c}{$\mathrm{P}$} \\
\cline { 2 - 3 } Narrowing LAD & $\mathrm{n}$ & $\%$ & & $\mathrm{n}$ & $\%$ & Value \\
\hline $0-50 \%$ & 12 & 30.0 & & 8 & 20.0 & $0.30^{\mathrm{NS}}$ \\
$50-70 \%$ & 3 & 7.5 & & 0.0 & $0.120^{\mathrm{NS}}$ \\
$70-90 \%$ & 20 & 50.0 & & 25 & 62.5 & $0.259^{\mathrm{NS}}$ \\
$>90 \%$ & 5 & 12.5 & & 7 & 17.5 & $0.531^{\mathrm{NS}}$ \\
\hline Total & 40 & 100.0 & 40 & 100.0 & \\
\hline
\end{tabular}

$\mathrm{NS}=$ non significant 
Table-VI

Distribution of the patients in both groups according to severity of lesions at $R C A(N=80)$

\begin{tabular}{lccccr}
\hline Severity of lesion & \multicolumn{2}{c}{ Group I } & \multicolumn{2}{c}{ Group II } & P \\
Narrowing RCA & $\mathrm{n}$ & $\%$ & $\mathrm{n}$ & $\%$ & Value \\
\hline $0-50 \%$ & 13 & 32.5 & 7 & 17.5 & $0.121^{\mathrm{NS}}$ \\
$50-70 \%$ & 1 & 2.5 & 3 & 7.5 & $0.301^{\mathrm{NS}}$ \\
$70-90 \%$ & 23 & 57.5 & 22 & 55.0 & $0.821^{\mathrm{NS}}$ \\
$>90 \%$ & 3 & 7.5 & 8 & 20.0 & $0.104^{\mathrm{NS}}$ \\
\hline Total & 40 & 100.0 & 40 & 100.0 & \\
\hline
\end{tabular}

$\mathrm{NS}=$ non significant

But distribution of pathological coronary anatomy type was found significantly different in both groups. Among 40 study patients (Group-I) normal coronary was found in 9 patients(22.5\%), type I in 11 patients(27.5\%), type II in 3 patients(7.5\%), type III in 3 patients(7.5\%) and type IV in 14 patients(35\%). On the other hand, in the control group(Group II) no patient had normal coronary artery, 27 patients $(67.5 \%)$ had type I, 2 patients $(5 \%)$ had type II, 9 patients( $22.5 \%$ ) had type III and only 2 patients (5\%) had type IV pathological coronary artery. Application of chi-square test showed type I pathological coronary anatomy in study population(Group I) significantly lower and type IV coronary anatomy significantly higher in study group(Group I) than control group(Group II) $(p=0.001)$.

\section{Table-VII}

Distribution of the patients in both groups according to pathological coronary anatomy in regard to blood supply of conduction system $(N=80)$

\begin{tabular}{lccccc}
\hline Type of lesion & \multicolumn{2}{c}{ Group I } & \multicolumn{2}{c}{ Group II } & P \\
& $\mathrm{n}$ & $\%$ & $\mathrm{n}$ & $\%$ & Value \\
\hline Normal & 9 & 22.5 & 0 & 0.0 & $0.001^{\text {*** }}$ \\
Type I & 11 & 27.5 & 27 & 67.5 & $0.001^{* * *}$ \\
Type II & 3 & 7.5 & 2 & 5.0 & $0.500^{\mathrm{NS}}$ \\
Type III & 3 & 7.5 & 9 & 22.5 & $0.060^{\mathrm{NS}}$ \\
Type IV & 14 & 35.0 & 2 & 5.0 & $0.001^{* * *}$ \\
\hline Total & 40 & 100.0 & 40 & 100.0 & \\
\hline
\end{tabular}

$* * *=$ significant at 0.001 level

$\mathrm{NS}=$ non significant

\section{Table-VIII}

Distribution of the subjects by flow quality in vessels supplying conduction system $(N=80)$

\begin{tabular}{|c|c|c|c|c|c|}
\hline \multirow[t]{2}{*}{ Flow quality } & \multicolumn{2}{|c|}{ Group I } & \multicolumn{2}{|c|}{ Group II } & \multirow{2}{*}{$\begin{array}{c}\mathrm{P} \\
\text { Value }\end{array}$} \\
\hline & $\mathrm{n}$ & $\%$ & $\mathrm{n}$ & $\%$ & \\
\hline \multicolumn{6}{|c|}{ Septal branches } \\
\hline Poor & 17 & 42.5 & 4 & 10.0 & \\
\hline Moderate & 13 & 32.5 & 20 & 50.0 & $0.001^{* * *}$ \\
\hline Good & 10 & 25.0 & 16 & 40.0 & \\
\hline \multicolumn{6}{|c|}{ SA nodal Branch } \\
\hline Poor & 2 & 5.0 & 0 & 0.0 & \\
\hline Moderate & 18 & 45.0 & 15 & 37.5 & $0.495^{\mathrm{NS}}$ \\
\hline Good & 20 & 50.0 & 25 & 62.5 & \\
\hline
\end{tabular}

AV nodal Branch

\begin{tabular}{lccccl} 
Poor & 17 & 42.5 & 2 & 5.0 & \\
Moderate & 15 & 37.5 & 18 & 45.0 & $0.001^{* * *}$ \\
Good & 8 & 20.0 & 20 & 50.0 & \\
\hline
\end{tabular}

$* * *=$ significant at 0.001 level

$\mathrm{NS}=$ non significant

\section{Table-IX}

Distribution of the patients in both groups by anatomic types that compromise blood flow the septal branches(II \& IV) and that do not (I \& III) $(N=80)$

\begin{tabular}{lccc}
\hline Pathological & $\begin{array}{c}\text { Group I } \\
(\mathrm{n}=40)\end{array}$ & $\begin{array}{c}\text { Group II } \\
(\mathrm{n}=40)\end{array}$ & P value \\
\hline coronary anatomy & & & \\
II \& IV & $17(42.5 \%)$ & $4(10 \%)$ & $0.001^{* * *}$ \\
I \& III & $14(35 \%)$ & $36(90 \%)$ & \\
\hline
\end{tabular}

$* * *=$ significant at 0.001 level

\section{Discussion:}

40 patients with conduction system disorder that required PPM and who had undergone coronary angiogram were included as the study patient (Group I). Another 40 patient who had coronary artery disease (CAD) but without conduction system disease and had undergone coronary angiogram were considered in control group (Group II). Control group were selected according to nearest possible values of the study patients in context of age, sex, presence of diabetes mellitus or systemic hypertension of LV dysfunction. Both 
groups were analyzed on the basis of pathological coronary anatomy regarding blood supply to the conduction system and flow quality was also assessed in the vessels supplying conduction system.

Conduction disturbances that indicated permanent pacemaker in study population $(n=40)$ was shown at Table IV. Mosseri et al. ${ }^{7}$ found highest number of complete atrioventricular block (20 of 43 patients) in their study which correlated with present study. Important to not here that in clinical practice large number of patients with rhythm disturbances was elderly and diagnosed as sinus node disease, which thought to be degenerative, and did not undergo coronary angiogram. So few patients with sinus node disease were included in our study.

There is still controversy about the association of conduction disturbances and underlying coronary anatomy. ${ }^{9}$ The relationship between the conduction disturbances and the underlying pathology has been studied at autopsy, but these patients do not represent the general population. Hambly et al. ${ }^{10}$ examined 42 patients with ECG conduction disturbances and symptomatic coronary artery disease. Although most patients had a significant lesion in the LAD coronary artery, there was no correlation with specific lesion.

In this study patients in the study group (Group I) and control group (Group II) had significant lesion at LAD or RCA but lesion was not found significantly different between two groups ( $p>0.05)$ Table V \& VI). This result is similar with the study done by Mosseri et al. ${ }^{7}$ and Tandogan et al. ${ }^{9}$

But location of the lesion regarding blood supply to the conduction system was found significantly different between two groups (Table VII). In our study type I lesion was found in 9 patients (27.5\%) of study group (Group I), on the other had type I lesion was found in 27 patients (67.5\%) of control group (Group II) (Table VII). Type I lesion was significantly lower in study group. Again in our study type IV lesion was found 14 patients (35\%) in study group (group I) whereas only 2 patients (5\%) in control group (Group II). Type IV lesion was found significantly higher in study group that the control group ( $\mathrm{p}=0.001$ ) (Table VII). This result was corresponded with Mosseri et al. ${ }^{7}$ and Tandogan et al. ${ }^{9}$
Mosseri et al. ${ }^{7}$ has reported that out of 37 patients who had conduction system disorder that required permanent pacemaker 16 patients (44\%) and Tandogan et al. ${ }^{9}$ also found that out of 78 patients with conduction system disorder that required PPM, 35 patients (45\%) had type IV pathological coronary anatomy which thought to be responsible for that conduction disorder.

In our study, though result is statistically significant $(\mathrm{p}=0.001)$ but percentage of type IV coronary anatomy (35\%) was found to be lower than in previous study (44\% and $45 \%$ ). In perspective of Bangladesh many patients with conduction system disorder that required permanent pacemaker were elderly and most of them were middle or low socioeconomic status. Many of them, after PPM implantation felt better and were not interested to further undergo coronary angiogram and further intervention if necessary, due to economic constraints. So in spite of proper indication large number of these patients refused coronary angiogram and so were not included in the study. This might be the cause of different in the study result from previous one.

Flow quality in blood supply of the conduction system i. e. septal branches (17 patients out of 40) and AV nodal branch (17 patients out of 40) was found poor specially those who had type IV pathological coronary anatomy in study population in comparison to control group (Group II) Table VIII) Again incidence of combined anatomic types that compromise blood flow to the septal branches (type II and type IV) was found significantly higher in study group than that do not (type I and type III) (Table IX). Though this result was consistent with Tandogan et al ${ }^{9}$ but not with Mosseri et al. ${ }^{7}$ Mosseri et al. ${ }^{7}$ found that there was a tendency for reduced flow in the conduction system supply branches in the study group, but this was not statistically significant.

According to them, thus diffuse atherosclerosis and lesion severity are not responsible for severe conduction disturbances. Rather, it is the location of the lesions along the coronary tree that compromises blood flow to the conduction system and might be responsible for their conduction disturbances. Out study result corresponded with their opinion. 


\section{Conclusion}

This study revealed that a significant number of study population i. e. patients with conduction disorder requiring permanent pacemaker had significant coronary artery lesion at specific site i. e. at left anterior descending artery compromising flow to the septal branches and also at right coronary artery compromising flow to the SA nodal or AV nodal branch which induced conduction system ischaemia that might be responsible for their rhythm disturbances and in addition to implantation of permanent pacemaker other therapy like coronary revascularization or optimization of medical therapy should be needed for better management.

This study may be the base of further clinical studies with larger population to validate our findings.

\section{References}

1. MN Islam, MA Ali, M Ali. Spectrum of Cardiovascular Diseases:The Current Scenario in Bangladesh. Bangladesh Heart Journal 2004;19(1):1-7.

2. JL Fleg, Right bundle branch block : long-term prognosis in apparently healthy men. J AM Coll Cardiol 1983; 1 : 887-892.
3. Rotman, M, 'A clinical and follow-up study of right and left bundle branch block', Circulation, 1975; 51: 477 484.

4. BE Kreger. Prevalence of intraventricular block in general population: the Framingham Study. Am Heart J 1989;117: 903-910.

5. W Robert, Peters, Heart block and Conduction Disturbances. Current Treatment Options in Cardiovascular Medicine 1999;1: 153-166.

6. C.Michael, Lewis, R Gilles, Dagenais, C Gttalib, Friesinger, S Richard, Ross. 1970, ' Coronary arteriographic Appearences in Patients with Left Bundle-Branch Block', Circulation 1970; 1.41: 299-307.

7. M Morris, I Tami, R Shimon, R Yoseph, Z Einat, A Dan, S Mervyn, Gotsman. Coronary Angiographic Characteristics of patients With Permanent Artificial Pacemakers. Circulation 1997; 96: 809-815.

8. JT Dodge, BG Brown, EL Bolson, HT Dodge.Lumen diameter of normal human coronary arteries. Circulation 1992; 86: 232-246.

9. I Tandogan, E Yetkin, Y Guray, Yuksel, Y Aksoy, AT Sezgin, R Ozdemir, S Cehreli, A Sasmaz.Distribution of Coronary Artery Lesions in Patients With Permanent Pacemakers. Anadolu Kardiyol Derg 2002; 4: 279-283.

10. RJ Hamby, F Tabrah, M Gupta. Interventricular conduction disturbances and coronary artery disease. Am J Cardiol 1973; 32: 756-765. 